\title{
Narrative Communication in Cancer Prevention and Control: A Framework to Guide Research and Application
}

\author{
Matthew W. Kreuter, Ph.D., M.P.H. \\ Health Communication Research Laboratory, School of Public Health Saint Louis University \\ Melanie C. Green, Ph.D. \\ Department of Psychology, University of North Carolina at Chapel Hill \\ Joseph N. Cappella, Ph.D. \\ Annenberg School for Communication and Abrams Cancer Center, University of Pennsylvania \\ Michael D. Slater, Ph.D. \\ School of Communication, Ohio State University \\ Meg E. Wise, Ph.D. \\ Center for Health Systems Research \& Analysis, University of Wisconsin-Madison
}

Doug Storey, Ph.D.

Center for Communication Programs, Bloomberg School of Public Health Johns Hopkins University

Eddie M. Clark, Ph.D.

Department of Psychology, Saint Louis University

Daniel J. O'Keefe, Ph.D.

Department of Communication Studies, Northwestern University

Deborah O. Erwin, Ph.D.

Division of Cancer Prevention and Population Sciences, Roswell Park Cancer Institute

Kathleen Holmes, M.P.H., R.N. and Leslie J. Hinyard, M.S.W.

Health Communication Research Laboratory, School of Public Health Saint Louis University

Thomas Houston, M.D., M.P.H.

Center for Outcomes and Effectiveness Research and Education, University of Alabama at Birmingham and Deep South Center on Effectiveness Research, Veteran's Affairs Medical Center, Birmingham, Alabama

Sabra Woolley, Ph.D.

Health Communication and Informatics Research Branch, Division of Cancer Control and Population Sciences,

National Cancer Institute

After the first author, the author order was determined by chance.

This article is a product of the National Cancer Institute (NCI) Working Group on Narrative Communication in Cancer Prevention and Control, which received support through NCI's Centers of Excellence in Cancer Communication Research (CECCR) initiative. Members of the interdisciplinary Working Group represent the fields of anthropology, communication, internal medicine, nursing, public health, social psychology, and social work. We are grateful to NCI for providing an opportunity to work together on this important issue.

Thanks to Danielle Davis from Saint Louis University for assistance in preparing the article.

Reprint Address: M. Kreuter, Ph.D., M.P.H., Health Communication Research Laboratory, Department of Community Health, School of Public Health, Saint Louis University, 3545 Lafayette Avenue, St. Louis, MO 63104. E-mail: kreuter@slu.edu

(C) 2007 by The Society of Behavioral Medicine.

\section{ABSTRACT}

Narrative forms of communication - including entertainment education, journalism, literature, testimonials, and storytelling - are emerging as important tools for cancer prevention and control. To stimulate critical thinking about the role of narrative in cancer communication and promote a more focused and systematic program of research to understand its effects, we propose a typology of narrative application in cancer control. We assert that narrative has four distinctive capabilities: overcoming resistance, facilitating information processing, providing surrogate social connections, and addressing emotional and existential issues. We further assert that different capabilities are applicable to different outcomes across the cancer control continuum (e.g., prevention, detection, diagnosis, treatment, survivorship). This article describes the empirical evidence and theoretical rationale supporting propositions in the typology, identifies variables likely to moderate narrative effects, raises ethical 
issues to be addressed when using narrative communication in cancer prevention and control efforts, and discusses potential limitations of using narrative in this way. Future research needs based on these propositions are outlined and encouraged.

(Ann Behav Med 2007, 33(3):221-235)

\section{INTRODUCTION}

Health communication is an important tool for helping achieve public health objectives, including prevention and control of cancer $(1,2)$. Traditionally, cancer prevention information has been presented in didactic and expository ways to educate, engage, persuade, or activate the public. More recently, narrative forms of communication are emerging as promising alternatives for achieving these and other outcomes $(3,4)$. Because there has not been a framework for organizing what is known (and not known) about how, when, and for what outcomes and audiences narrative health communication might be most effective, this article proposes a model of narrative effects in cancer communication. We hope the article will stimulate critical thinking about the role of narrative in health communication, promote a more focused and systematic program of narrative research in cancer communication, and help accelerate translation and application of narrative research findings into practice to help reduce the burden of cancer.

\section{What Is Narrative Communication?}

In large part, the promise and appeal of narrative lies in its familiarity as a basic mode of human interaction. Because people communicate with one another and learn about the world around them largely through stories, it is a comfortable way of giving and receiving information. For the purpose of this article, we define narrative as "a representation of connected events and characters that has an identifiable structure, is bounded in space and time, and contains implicit or explicit messages about the topic being addressed." This definition integrates key elements of narrative as described in the literature (5-7) and captures a wide range of narrative types including "entertainment education" (using forms of entertainment such as soap operas, cartoons, or dramas to educate the public about health or social issues) (8), reporting and journalism, literature, case histories, testimonials and storytelling.

In contrast, nonnarrative would include expository and didactic styles of communication that present propositions in the form of reasons and evidence supporting a claim. Both narrative and nonnarrative forms of communication can carry the same cancer prevention and control message, but a narrative will do so by representing a sequence of connected events, characters, and consequences, not by presenting and defending arguments about how and why to achieve or avoid those consequences. Although there is no clear consensus among scientists on the conceptual differences between narrative and other forms of communication (9), we believe the distinction made in this article has practical value for understanding and enhancing the effectiveness of cancer communication.

\section{How Can Narrative Help Eliminate Suffering and Death due to Cancer?}

The overarching goal of the National Cancer Institute (NCI) is to eliminate death and suffering due to cancer by 2015. In cancer prevention and control, the strategies to help meet this goal are classified along a "Cancer Control Continuum" that spans five sequential areas of the cancer experience: prevention, detection, diagnosis, treatment, and survivorship (10). The Continuum identifies "communications" as one of nine crosscutting issues that can influence outcomes in each of the five areas. It is clear, however, that significant communication-related challenges must be overcome to make progress in cancer control. Current health communication tactics have not adequately addressed diverse populations or health disparities (11), many Americans do not understand health information well enough to make informed decisions or act on it (12), cancer survivors and their family members are often unsatisfied with the health information they receive or can access (13), and traditional expository forms of communication are poorly suited for addressing certain fundamental needs of cancer patients like prioritizing values and managing social relationships (14).

Using the Cancer Control Continuum as an organizing framework, we explored how the crosscutting theme of communications, specifically as it related to narrative approaches, might address such challenges. We posed two questions: What are the distinctive capabilities of narrative that differentiate it from other forms of communication, and how do these capabilities influence outcomes of interest across the Cancer Control Continuum? In answering the second question, we reduced the five focus areas on the Cancer Control Continuum to two broad categories: prediagnosis (i.e., prevention, detection) and postdiagnosis (i.e., diagnosis, treatment, survivorship). The resulting typology of narrative capabilities by cancer control outcomes is shown in Table 1.

As the table shows, we identify four distinct capabilities of narrative: overcoming resistance, facilitating information processing, providing surrogate social connections, and representing emotional and existential issues. We acknowledge that all four capabilities may influence outcomes across the Cancer Control Continuum but propose that some have primary value in addressing either pre- or postdiagnosis issues. Specifically, we assert the following:

1. Narrative communication can influence prediagnosis outcomes such as cancer-related lifestyle behaviors (e.g., diet, physical activity, tobacco use, sun protection) and cancer screening (e.g., mammography, Pap test, 
TABLE 1

Typology of Narrative Communication Capabilities Applied Across the Cancer Control Continuum

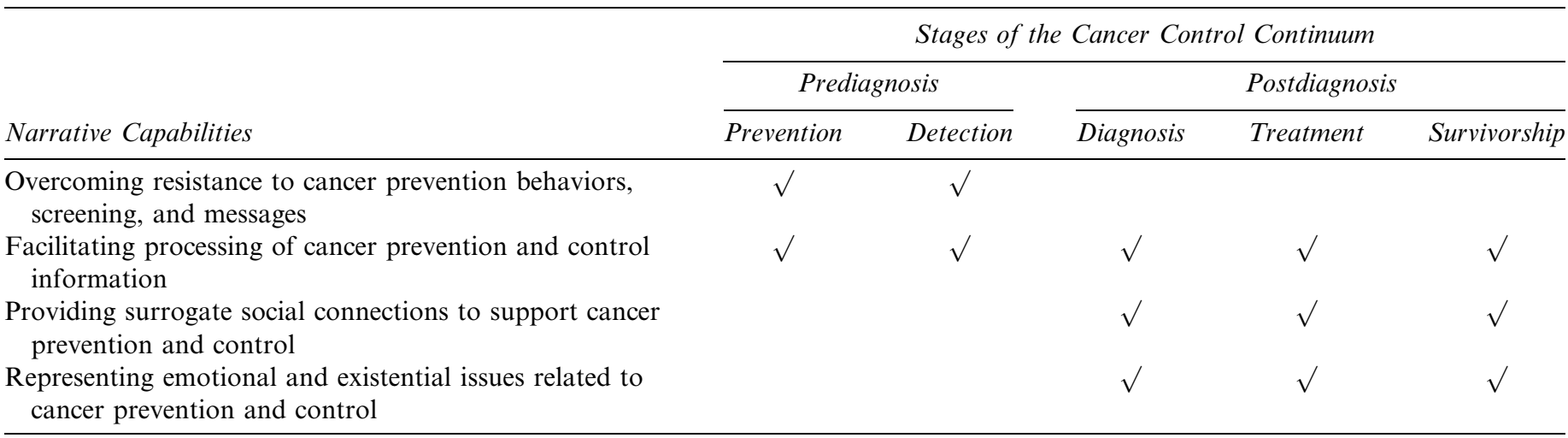

sigmoidoscopy, fecal occult blood test, prostate-specific antigen test) by overcoming resistance (e.g., counter attitudes and beliefs) to adopting or maintaining these behaviors.

2. Narrative communication can influence postdiagnosis outcomes such as informed decision-making, coping and support by providing surrogate social connections for those affected by cancer and by addressing emotional and existential issues surrounding cancer diagnosis, treatment, and survivorship in ways that help those affected by cancer maximize the length and quality of their lives.

3. Narrative communication can influence both pre- and postdiagnosis outcomes by facilitating processing of cancer prevention and control information.

Empirical evidence and theoretical rationale supporting these propositions are presented in the following sections, as are some potential limitations or drawbacks of using narrative in this way. Because there has been limited research on narrative health communication that is specific to cancer, the evidence base draws heavily on noncancer studies and general persuasion literature. We emphasize that this typology has not been directly evaluated and strongly encourage narrative cancer communication research that is based on its propositions. The typology suggests two broad areas of inquiry, corresponding to the axes in Table 1. First, is narrative indeed more effective than nonnarrative communication for overcoming resistance, facilitating information processing, providing social connections, and representing emotional and existential issues? Second, do these mechanisms through which narratives may influence cancer-related outcomes differ for individuals who are pre- versus postdiagnosis? Specific research questions are introduced within the sections below describing each component of the typology. Finally, we describe variables that may moderate the effects of narrative and ethical issues that should be considered when using narrative communication in cancer prevention and control efforts.

\section{CAPABILITIES OF NARRATIVE}

\section{Overcoming Resistance to Cancer Prevention and Control Information}

Narrative forms of communication might enjoy some special advantage over more didactic forms for addressing particular bases of resistance to cancer prevention or detection behaviors or information. Resistance can be broadly defined as a reaction against change, or a motivation to oppose persuasive appeals (15). Resistance may be a particular concern for prediagnosis behaviors such as cancer screening because some individuals are likely to be highly motivated to maintain an illusion of invulnerability.

It is useful to distinguish the ways that persons might resist adopting a cancer prevention or cancer-detection behavior from the ways that persons might resist cancerrelated messages. Resistance to behaviors might include denying the effectiveness of the behavior or simply refusing to take an action. Resistance to persuasive messages may include counterarguing the message claims, ignoring the messages altogether, or denying the validity of the message due to the message source.

Resisting cancer-related behaviors. There are many reasons that persons fail to undertake behaviors that might minimize their cancer risks or permit early detection of (pre-) cancerous conditions. At least some of these bases of resistance might be addressed using narrative forms of communication. One common basis of resistance to cancer prevention behaviors is a lack of perceived self-efficacy. Studies of cancer-related and other behaviors have indicated that modeling (seeing similar others successfully perform the behavior) may be a mechanism for influencing perceived self-efficacy (e.g., 16,17). A narrative format can straightforwardly convey modeling information by telling the story of a person who was able to successfully perform the action. (For an illustration of the potential of modeling to influence self-efficacy concerning breast self-examination, see 18). 
If individuals know what to expect from a procedure (e.g., what it's like to get a mammogram) they may be better able to prepare for engaging in the behavior. Modeling has been widely and successfully used in entertainment education, much of which has addressed health issues (19).

As another example, some people might resist undergoing cancer screening because of doubts about response efficacy, that is, because they are unconvinced that screening can actually save their life. But a compelling personal narrative conveying the benefits of early detection might be more convincing than recitation of statistical information. And persons who doubt the potential severity of cancer might be especially convinced by hearing firsthand reports of cancer patients. A classic example is the 1985 public service announcement by Academy Award winning actor Yul Brynner, a lifelong smoker who died of lung cancer, urging people not to smoke (see http://www.yulbrynnerfoundation.org/psa.htm).

Narrative forms of communication will not always be the most appropriate way to address these behavioral barriers, and too little is known about exactly what aspects of narrative messages might make them more valuable for addressing one or another barrier. For instance, only a few cancer-specific studies have examined which characteristics of models influence their effectiveness in altering self-efficacy perceptions (e.g., 20); sometimes even cancer narratives that stimulate highly positive attitudes and intentions about screening are not significantly more effective in doing so compared to didactic formats (e.g., 21). But narratives plainly can be a powerful means of influencing behavior, and it will be useful to have additional research that identifies the conditions and characteristics that make narrative formats especially potent.

Resisting cancer-related messages. Exposure to a persuasive communication does not guarantee acceptance of the message's claims. One common way in which people resist persuasive communications is counterarguing, or disputing message claims and implications. Counterarguing can be reduced if individuals are immersed in a story, or transported into a narrative world (22). For instance, Slater and Rouner found that in processing alcohol education messages, college students rated statistical evidence as more persuasive when the message was congruent with their values, but narrative evidence as more persuasive when the message was incongruent with their values (i.e., counterattitudinal) (23). Transportation may reduce individuals' ability to counterargue story assertions, because the reader's mental capacity is devoted to imaging story events. It may also be more difficult to counterargue conclusions that are implied by the story rather than stated directly as arguments. Transportation may also reduce individuals' motivation to counterargue, because interrupting the narrative flow to dispute the author's claims or descriptions would likely destroy the pleasure of the experience.

Because narratives tend to be concrete, presenting the lived experience of others, it may also be more difficult to discount them $(19,24)$. Indeed, people tend to generalize from a narrative exemplar even when the presented case is not typical $(25,26)$, perhaps because of its vividness (27). This feature of narrative has long been recognized in political communication, where (for better or worse) policy anecdotes can trump statistical data (28). In health communication, studies show that cancer-related celebrity news stories can increase interest in, and use of, cancer screening tests (29-31). Cancer educators thus need to consider the appropriate use of narratives as well as encouraging individuals to be critical consumers of narrative.

Narratives may also reduce resistance, because they are a relatively subtle form of persuasion (32). In many narratives, individuals may not be forewarned of the persuasive intent, and thus may not marshal their cognitive resources to defend against a potentially counterattitudinal message. Individuals drawn to a narrative by its plot, interest, or entertainment value can then be affected by cancer-related information in the story. In a similar way, narratives may be less susceptible to selective exposure; individuals may not actively avoid a narrative with an antismoking subplot in the same way that they might avoid an antismoking pamphlet, for instance. This benefit of narrative is likely more applicable to the prediagnosis state, as postdiagnosis individuals are likely to be actively seeking information rather than avoiding it.

Narrative health messages should not be so subtle that individuals miss the point, however. (Indeed, when there is an immediate need for directive communication, such as emergencies, simple nonnarrative communications would be preferred.) If individuals are not drawing appropriate inferences about cancer-related behaviors, a narrative will be ineffective. Finding the balance between entertainment and education in narratives is an important practical issue. How strong the explicit message can be without encouraging reactance is an empirical question and may depend on factors such as the resistance level of the audience, existing connections the audience has with the characters or narrator, and the quality of the narrative.

Individuals might also resist cancer-related messages due to fear. They do not want to think about the possibility of a life-threatening illness, and so they avoid the topic altogether rather than experiencing an unpleasant emotional response. Narratives may be less threatening and thus less likely to engender avoidance or selective exposure under these circumstances. Future research might explore the efficacy of narratives in both assuaging fear of cancer (e.g., by showing that breast cancer is survivable) and creating fear when appropriate (by showing that cancer is a real and serious threat). 
Although health care providers are a traditional source of health information, adherence to provider messages depends on trust in the provider. Distrust may cause increased resistance to provider-delivered messages. Because distrust is often highest in minority populations that suffer a disproportionate burden of cancer (33), using narrative to overcome such resistance may be an important tactic for helping eliminate cancer disparities. Narratives may also be useful in reducing resistance to provider-delivered messages postdiagnosis, for example, when individuals are considering treatment options.

Sometimes persuasive efforts can fail because of a lack of perceived message relevance. There is some evidence that narrative forms might be especially helpful in addressing this problem. Cox and Cox compared two forms of messages aimed at encouraging mammography, a "statistical" version (e.g., "Many women have no family history of breast cancer and have never felt any lump in their breast") and a parallel narrative version ("No one in Sara Johnson's family had ever gotten breast cancer, and she had never felt any lump in her breast") (34, p. 95). The narrative version was significantly more engaging to participants (as indexed by responses to items such as "The ad's message seemed relevant to me" and "I got involved in what the ad had to say"). But, as an indication of how much is yet to be learned about narrative forms of health information in this context, the narrative message had no general advantage over the statistical one with respect to influencing mammography beliefs, attitudes, or intentionsperhaps, per Slater and Rouner (23), because the participants were not for the most part particularly resistant to the message provided.

Future research. Existing research illustrates the potential of narrative approaches. Future work should help specify when and how narratives can be most effectively used to overcome resistance to cancer messages and behaviors. For example, does the relative effectiveness of narrative versus didactic forms of communication vary under conditions of mild versus extreme resistance? What attributes of characters or messengers in cancer-related narratives enhance the likelihood of increasing self-efficacy or other desired outcomes among those exposed to the narrative? Finally, under what conditions does becoming more engaged in a narrative lead to greater persuasive impact, and when does engagement impede or have no effect on belief or behavior change?

\section{Facilitating Processing of Cancer Prevention and Control Information}

Communication strategies that increase attention to and facilitate comprehension of cancer information should enhance outcomes across the cancer continuum. To understand this potential, two points should be considered. First, narrative is storytelling. Second, storytelling is representation of social information and social experience-the kind of information that human beings process from infancy without the need for education and training (other than learning to read, in the case of narratives presented in the form of written text). In other words, humans may be "hardwired" to process the kind of social information presented in narratives; there is substantial evidence that social information is stored in memory in narrative forms such as scripts, and that such information has distinct advantages with respect to memory and recall (see Green, Strange, \& Brock [35] for reviews of this literature).

Therefore, there is good reason to believe that use of stories or other forms of narrative has the potential to facilitate attention, comprehension, and recall of cancerrelated information. These advantages may be of modest importance when the audience for such information is highly motivated (as might be the case among individuals already diagnosed with cancer) and has the education or experience with which to make sense of complex, didactic information. However, for other audiences, including people with limited numeracy skills, lower health literacy, lower self-efficacy for understanding information, those who mistrust medical authorities because of their cultural or economic difference from themselves, and those from cultures that define knowledge or wisdom primarily as that which is gained through lived experience, narratives may be of particular utility (e.g., 36).

Although the ability of narratives to model desirable behaviors, increase self-efficacy about enacting health behaviors, and address social and cultural obstacles to health behavior change is increasingly well studied and well documented, the ability of narrative to increase attention to, comprehension, and recall of important cancer information has not been extensively researched. Narrative may have the potential to increase attention and processing of messages, especially when intended recipients have limited ability, motivation, or interest in processing more didactic messages. Such limitations may be commonplace when communicating to the general public about primary and secondary prevention behaviors, given the many competing demands for attention in this media-rich society.

Moreover, the use of narrative might prove of particular value to all individuals irrespective of education or motivation during diagnosis and treatment, when overwhelming emotions are arising and focusing on complex didactic information may be difficult. For example, stories of patients and families from similar social contexts facing similar situations might make it much easier to take in and later to recall ways to cope with survivorship issues, treatment side effects, complex medical decision making, and end-of-life issues.

Future research. Exploring the use of narrative to increase attention, comprehension, and recall of cancerrelated information has considerable potential but a 
surprisingly sparse research base. Research to guide use of narrative for these purposes might address a wide range of questions. For example, one strength of stories is that they have the credibility of representing someone's lived experience. But can the idiosyncratic nature of that experience lead to distortion or overemphasis? In stories explaining cancer treatment choices, for example, might an audience member's attention, recall, and response be influenced by how he or she reacts to those portrayed in the story as much as by the relevance of the information to his or her own situation? If so, how can cancer communicators utilize the processing advantages of narrative while preserving the integrity of the information they wish to convey?

If narrative indeed enhances information processing among underserved groups (who may or may not have been reached by other forms of cancer information), it could be an important tool for addressing health disparities. If this is the case, how close must the "match" be between the characters in a narrative (or person providing a firsthand account) and the audience of interest? The closer the match required, the more extensive the range of narratives needed and the more careful the tailoring must be to match audience to story. A final challenge for research concerns the balance of information comprehensiveness and narrative structure. A story may provide memorable and easily understood information but not cover all dimensions of a topic (e.g., all the pros and cons of a given treatment). When the latter is required, how best can narratives be employed? Are there key points that can be emphasized in a narrative, and if so, does this aid recall of the entire structure of information provided?

\section{Provide Social Connections Relevant to Cancer Prevention and Control}

People develop relationships with characters in literature, stories, news, and other ongoing vicarious mediated experiences, even when the characters are fictional. These characters can provide a kind of pseudorelationship for the audience member, sometimes called a "para-social" relationship. Social support from real persons in face-toface and mediated contexts (e.g., online support groups) is known to have significant benefits to both physical and mental health. We propose that para-social relationships that can be created through narratives have the potential to provide health benefits similar to those of real social support, at least under some conditions.

By para-social, we mean identification with media personalities, real or fictional, and a sense of friendship, attraction, and involvement with the person or character (37). The concept of para-social relationship, introduced by Horton and Wohl (38), suggests that viewers can respond to characters and personalities in the media as they do to real social characters. Although it would be easy to dismiss para-social interaction (PSI) as some kind of social pathology of the lonely and incompetent, research on nonhealth topics suggests PSI can be as evocative, emotional, and informing as face-to-face social relationships (39). The PSI evoked by modern media characters parallels connections created with literary figures throughout history (40) and thus is simply a modern instantiation of what has long been an important and common identification between audiences and characters.

Do para-social and real relationships differ in their consequences? Para-social relationships evoke emotional involvement (41) and identification with characters (42). Harrison studied attraction to thin characters on television by young women and found an association with body image attitudes (43). Connection to thin media characters was associated with disordered eating symptoms. Identification with media characters can also affect audience responsiveness to messages about health (44). Magic Johnson disclosed that he was HIV-positive, and one simply knowing this fact and knowing of Johnson did not lead to increased concern about AIDS, HIV, or intentions to engage in less risky sexual behavior. But those who identified with Johnson emotionally did realize these outcomes. In general, those who identify with media characters pay more attention to programming, have more thoughts about the programs after viewing them, and are more likely to discuss the content of programs (37).

We hypothesize that para-social relationships developed through narrative encounters with sympathetic and involving characters - real or fictional - can have similar effects to the support provided by real social relationships. An impressive body of empirical evidence indicates that social support provides both physical and psychological benefits, including reduced susceptibility to disease, lower blood pressure, and better mental health $(45,46)$. Those receiving support may also have higher esteem, self-control, and better moods, all known to affect cardiovascular, endocrine, and immune system functions (47). It is important to note that these benefits are accrued not only by actual receipt of social support but also by perceiving that one has socially supportive others on whom they can depend (48). But what should we conclude about increasingly less personal forms of social support? As Giles wrote, "many attributes of PSI are similar to those of social interaction. ... PSI may arise from an altruistic human instinct to form attachments with others, at no matter how remote a distance" $(49$, p. 284$)$.

Social support delivered by initially anonymous others employing modalities such as online communications is at least a step removed from face-to-face communication. In online support groups, participants are often anonymous. The information they provide about themselves reduces anonymity, but participants seldom meet, even vicariously through one-to-one e-mail interactions. Despite the absence of face-to-face interaction, as rich as it is with nonverbal cues of emotion, involvement, and personal - even 
visceral-identification, anonymous supportive interaction online is linked to perceptions of social support and reports of social support received for health and other concerns (5052). Online interaction is still interaction, even when it is delayed for minutes, hours, or days. Despite distance, staggered, or delayed sequence of exchange, and the potential absence of sensory cues, relationships are unquestionably established in online cancer support environments (53). What makes online social support effective - when it is effective - is that it is responsive to the other's needs, sometimes called person-centered communication (54).

When narrative is simply a vehicle for providing information about cancer, even the most sympathetic character and involving story line may not approach the responsiveness of human partners online. However, this absence of responsiveness in passive but well-formed narratives does not seem to be a barrier to establishing surrogate social relationships with characters in narratives. Identification with a protagonist in a narrative can provide the kind of para-social interaction that allows some individuals to experience a sense of social support from others in like circumstances and whom they perceive as similar to themselves. The truth of this claim can only be resolved empirically, but it is a fair empirical question to ask.

Effects of PSI established through narrative cancer communications likely vary by type of social support, though this expectation is also as yet untested. Instrumental support such as bringing chicken soup, running errands, and helping with childcare often requires physical presence that PSI cannot provide. But emotional, informational and appraisal forms of social support can be provided in mediated and vicarious ways, not just face to face (55). For example, a breast cancer survivor narrative in which a woman recounts her initial feelings of despair upon hearing her diagnosis might provide a form of emotional support to a woman newly diagnosed with breast cancer by validating her own similar feelings. A story from the same survivor about how she gathered and weighed the pros and cons of reconstructive surgery might introduce ideas and identify resources (i.e., provide informational support) that would help another woman facing the same decision. Finally, stories delivered through an interactive system could provide constructive feedback, affirmation, and social comparison information (i.e., appraisal support). Matching the topic of a narrative with the unique social support needs of different individuals should maximize potential benefits of narrative and PSI and is technologically possible using tailored communication methods if a large library of narratives was available and audience needs for specific types of emotional and informational support could be reliably assessed (56).

Individuals who might benefit most from social support narratives include those whose own social networks are limited in scope or lack members having firsthand experience with cancer-related issues; who suffer from severe social anxiety; or who feel more comfortable with the anonymity of reading, watching, or hearing about others who have coped with similar cancer-related issues. When a person is uncomfortable in real social interaction, narrative might provide a beneficial substitute. For example, Papachirissi and Rubin found that socially anxious individuals used the Internet for chatrooms and online newsgroups, whereas outgoing individuals used the Internet for information (57).

Future research. Research on the effectiveness of cancer narratives in providing social support is lacking. We do not know whether narratives about how people have dealt with cancer risks, diagnoses, treatment, and posttreatment care will offer a sense of support or promote identification with the protagonist and under what conditions these possible effects might be optimized. If cancer narratives provide a social support benefit, it should be identifiable in mediating factors like decreased uncertainty about cancer decisions, increased self-efficacy to cope with cancer, and an increased sense of control and being a part of a (virtual) community. Other outcomes might include seeking information and support after a cancer diagnosis, satisfaction with treatment decision making, compliance with treatment regimens, coping with side effects of treatment, coping with recurrence, adherence to follow-up care, and getting on with life as a survivor.

It also seems possible that social support provided though some forms of narrative might feel less personalized, relevant, and salient than support provided in the other contexts. Could cancer narratives that are selected to match (i.e., are tailored) to diagnosis, gender, age, and other circumstances of audience members reduce the possible sense of depersonalization compared to general narratives? Better understanding the differences between narrative, online, and face-to-face support will help identify and refine appropriate roles for narrative cancer communication.

\section{Addressing Emotional and Existential Issues}

The study of emotional and existential issues - and narrative itself-has long been in the domain of humanities and humanistic therapies. This literature has focused more on storytellers' cancer experience than on audience effects. But in light of the potential power of narrative to create para-social connections, we believe this literature provides insights into how authentic, well-honed narratives might convey to audiences the emotional and existential complexities of cancer from diagnosis to end of life issues more effectively than expository communication - and thus enhance existential meaning making and coping with cancer.

Emotional and existential dilemmas of cancer and the paradox of personal growth. Cancer is an uninvited and unwelcome life event. It can strain relationships, erode 
one's sense of self, force unwanted decisions, dash one's sense of certainty and control over the future, and bring one face to face with one's deepest fears, death, and existential angst $(58,59)$. Timeworn and comfortable assumptions no longer work (60), as one must continuously renegotiate one's sense of self in the unfolding emotional and existential challenges from cancer diagnosis through survival or the end of life (61).

The popular (62) and scholarly literature (63) is replete with stories of cancer journeys with despair, quests for meaning, personal growth, and spiritual transformation. The scholarly literature suggests that in spite and because of suffering, cancer can deepen one's relationships, selfappreciation, and purpose and meaning in life (64). Such transformation entails holding and celebrating contradictions. Western culture privileges logical deductive consistency (65), but humans construct their experiences and sense of self through multiple lenses - emotional, existential, psychosocial, and physiological — and thus hold simultaneous and "contradictory" narratives about the same phenomenon (66). Cancer narratives are no exception (67).

Benefits of narrative learning and communication. Narratives - with their use of folk language and literary techniques - can express the nuances, contradictions, and aesthetics of illness and cancer's existential dilemmas more effectively than didactic formats $(6,66)$. Carlick and Biley identified six ways in which they may do so (67). First, narrative's temporal structure can impose a sense of order over the chaos that cancer imposes (66). Second, the storytelling process itself can provide the distance and perspective needed to view cancer as a series of solvable problems or a life event with opportunities to make positive life changes $(63,66,68,69)$. Third, life review narratives that highlight relationships, accomplishments, and values can enhance dignity as cancer erodes it and lay the groundwork for a tangible life legacy product (70). Fourth, in quest, hero, or recovery narratives, people cast themselves as adventurous protagonists who try new approaches and adopt dramatic metaphors in their fight against cancer $(63,66)$. Fifth, the story of illness, suffering, loss, and redemption can be told beautifullyor at least powerfully. Thus aesthetic narratives that resonate with a deeply shared human experience can benefit and inspire both story creator and audience (71).

Finally, "polyphonic" (or many-voiced) narratives articulate the human complexity associated with cancer $(66,67)$. That is, people hold many contradictory thoughts and feelings about cancer and death and dying. Paradoxically, people simultaneously hope and despair; accept, fight, and deny a terminal diagnosis; and recognize psycho-spiritual benefits in spite and because of tragedy and suffering $(72,73)$.
Several intellectual traditions, such as existentialism $(70,74)$, complexity theory $(75,76)$ and symbolic interactionism $(77)$, recognize and celebrate that individuals have many voices as they process their sense of self through several emotional, psychological, and social lenses. "Many-voicedness" demonstrates that dialectical integration of logical deductive reasoning, emotions, intution, and creativity is essential for existential meaning making and the development of wisdom $(70,78,79)$. In sum, polyphonic narratives may express deeper understanding of emotional and existential aspects of cancer and better portray the complex processes that lead to an enlightened resolution than might simpler narratives or expository forms of communication.

Narrative interventions that address emotional and existential issues associated with cancer. Research has focused primarily on how narrative interventions affect the storyteller. Benefits include improved emotional, psychological, and existential well-being; perceived social support; physical symptoms, cortisol levels, immune function; and survival time (70,72,80-82). The mechanisms of effect include insightful emotional expression, realistic optimism, and providing support to others $(69,72,74,83)$, as well as a temporal orientation of a hopeful present $(66,67)$. These findings, however, are limited by considerable variability in measures, study design, and approach (e.g., existential and/or cognitive behavioral).

Fewer studies have investigated audience effects. Chelf et al. found that cancer patients and their families reported that listening to other cancer patients' stories provided a sense of hope and confidence in facing their problems (84). By contrast, Coreil and colleagues found that some members of breast cancer support groups resisted the culturally dominant optimistic breast cancer recovery narrative with metaphors of personal growth and sisterhood (85) —in keeping with Spiegel's cautions against the "prison of positive thinking" (74).

Future research. This section has focused primarily on how telling one's cancer story can have beneficial effects for the storyteller, including coping with the emotional and existential complexities people face at different points along the cancer control continuum. Research is needed to determine whether similar benefits are gained by those exposed to such stories and whether these benefits might vary systematically by characteristics of a narrative, characteristics of a receiver, and/or interactions between the two. For example, do different types of narrative (e.g., hero vs. polyphonic) have different effects for different individuals? How do real-life personal stories compare to artistic, fictionalized, or composite narratives? What aspects of narrative quality and presentation format are most salient when addressing emotional and existential issues? What dimensions of similarity between audience members 
and narrative characters are likely to maximize coping with emotional and existential issues? Answers to questions like these will help researchers understand if and how narratives can help individuals and families face the uninvited challenges of life after a cancer diagnosis.

\section{POTENTIAL MODERATORS OF NARRATIVE EFFECTS}

The capabilities of narrative described in previous sections will only be realized if a story is "told well"- what we refer to as narrative quality. This section introduces narrative quality as the selection or crafting of narrative elements for a particular communication in a manner that enhances the narrative experience and narrative effects. We also identify and describe other moderating factors likely to enhance or diminish effects of narrative cancer communication.

\section{What are the Attributes of a "Quality" Narrative and why is Each Important?}

Messages may have the attributes of narrative (i.e., sequenced events, characters, time, location, etc.), but these alone do not guarantee effectiveness in achieving cancer prevention and control objectives. How these attributes are represented, sequenced, framed, and matched to audiences and objectives make the difference between a story told well and a story told poorly. Although the extent to which quality translates into effectiveness may vary depending on the situation, application of narrative, and how narrative is perceived by an audience, we believe that some message attributes are generalizable aspects of quality (see Table 2).

We organize these attributes according to the characteristics we used to define narrative: sequence, character, structure, bounded in space and time, and production techniques. Some of the attribute terms (coherence, canonical violation, fidelity/realism) derive from similar features of narrative described by Bruner (86). Other attribute terms (e.g., imagery, plot development) derive from theories of drama $(87)$ or scriptwriting $(88,89)$ and experience of the authors in applied health communication. Theoretical adherence, for example, enhances quality, because theoretically posited effects are more likely to occur if a narrative message conforms to specific relationships described in theoretical models. In creating entertainment-education narratives, scriptwriters commonly gloss over or ignore well-tested theoretical relationships in favor of telling what they consider to be a good story. Although it is not easy to craft a good story that is consistent with theory, a mismatch often compromises communication effectiveness.

Some of these attributes have been tested in message effectiveness research, but few have been tested in the context of narrative communication specifically. Evidence of how they work in narrative compared to nonnarrative messages is limited. Even more limited is empirical evidence of how these elements work independently versus in combination to produce desired health outcomes. Thus Table 2 suggests many possible research questions worth testing.

We are not necessarily advocating for research that deconstructs narrative quality. On the other hand, we believe that quality must be considered when developing narratives to achieve specified health outcomes. Having an inventory of attributes known to contribute to quality in particular ways will help health communicators assess strengths and shortcomings of a narrative and take steps to improve the chances of success. Narrative research should evaluate and compare materials that possess certain elements and combinations of elements so that appropriate choices can be made. Narrative research can build on the enormous body of message effectiveness research while continuing to develop operational definitions and measures of attributes of quality narrative that have received less attention historically.

\section{Other Moderating Factors that may Enhance or Diminish Narrative Effects}

We propose that perceptions of the source or messenger of a narrative, the transparency of persuasive intent, and whether a narrative is fiction or nonfiction are potentially important moderators of narrative effects. Where indicated and when possible, cancer communication researchers should hold them constant across comparison conditions and/or measure them and account for their effects.

Perceptions of the narrative source or messenger. Perceived similarity refers to receivers' judgments about how similar a narrative source is to them. These judgments may be based on actual or perceived characteristics of the source, such as socioeconomic status, group membership, place of residence, life experience, or attitudes, beliefs and values (90). The moderating effects of perceived similarity may be explained by social attractiveness - we tend to like people who are similar to us (91). Similarity may act as a peripheral cue and enhance narrative effectiveness when absorption into a narrative is low (22). Effects of similarity may be greater when attitude-relevant knowledge is low (92). For example, if an African American woman hasn't thought about breast cancer because she perceives it to be a "White woman's disease," exposure to autobiographical narratives from African American women similar to her may help change her attitude-relevant knowledge (93).

Perceived similarity may also influence narrative effects through identification. Slater and colleagues found that identification with characters moderated effects of message type (conversational vs. testimonial vs. newsletter) on believability, usefulness, and clarity of dietary change 


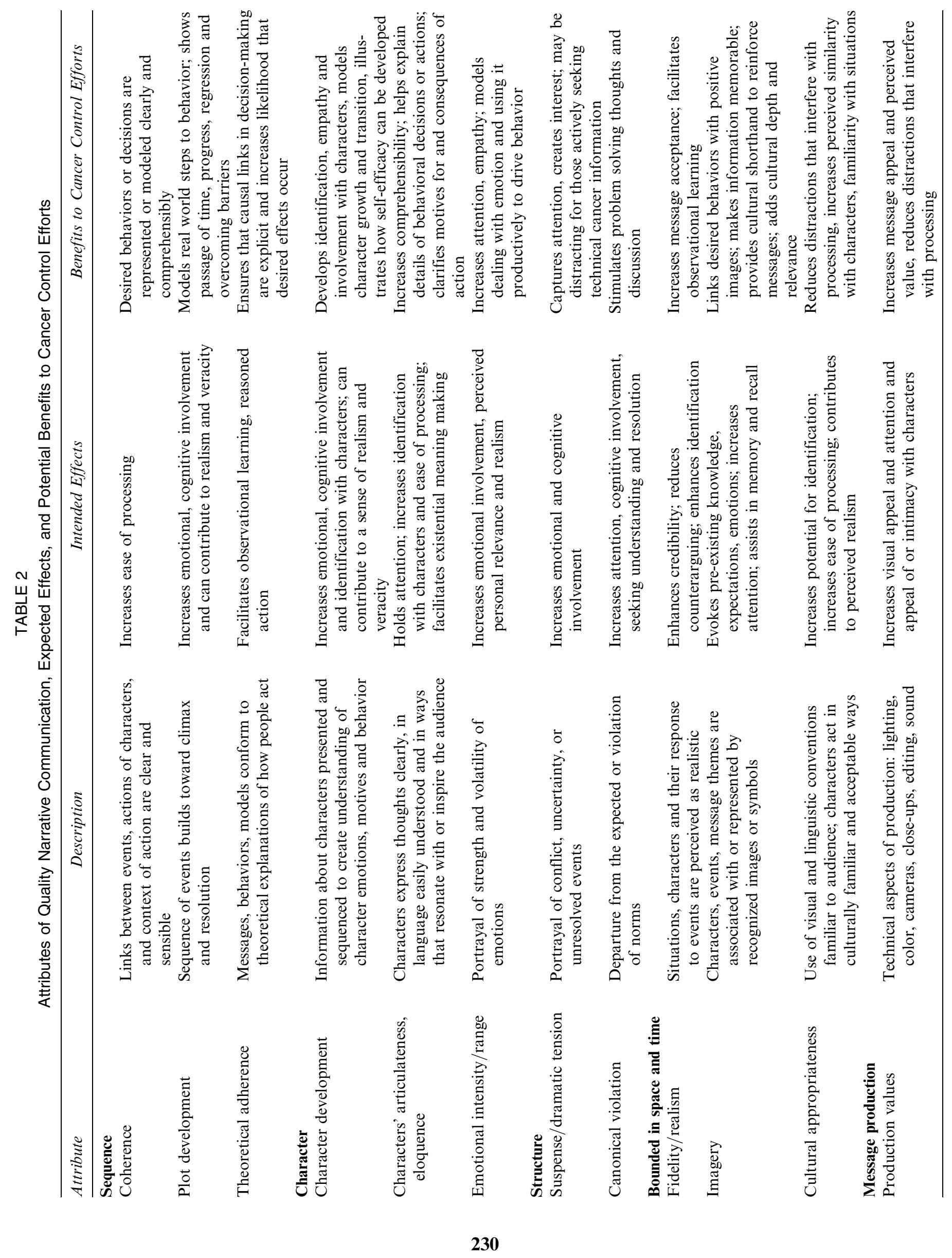


information (94). Identification with characters in narratives may also increase perceived susceptibility to cancer and empathy for those with cancer. Campbell and Babrow found that empathy mediates the relationship between exposure to HIV prevention messages and perceptions of HIV risk (95), and Shelton and Rogers showed, in a nonhealth-related study, that empathy-arousing appeals can facilitate attitude change (96).

Finally, perceived similarity to narrative characters may influence one's perception of social norms regarding cancer-related behaviors. For example, if main characters in a narrative had been recently screened for colorectal cancer, audience members may conclude that most people get these tests $(4,94)$. Social psychology research not specific to health suggests such a finding may also be due to belonging, trust of others in their ingroup, and conformity (97).

Perceived credibility of a source, messenger, or characters in a narrative is based on expertise and/or trustworthiness. Both can be established by a character's lived experience (e.g., as a cancer survivor), not just by his or her professional credentials (e.g., being a physician or nurse). Thus, especially in personal experience narratives, a messenger may be perceived as both an expert and trustworthy (98). Because expertise often acts as a peripheral cue (99), its effects may be greater when the audience is less absorbed in a narrative.

Transparency of persuasive intent. The extent to which underlying goals of a narrative (e.g., to increase cancer screening) are explicitly stated may moderate narrative effects. Persuasive intent is not always transparent in narratives (22). As a result, those exposed to engaging narratives are more likely to be absorbed in the story and suspend disbelief, less likely to cognitively defend against the narrative, and thus more open to attitude change. It is also possible, however, that these same factors will lead some to miss the health messages imbedded in a narrative. Slater proposed that an epilog at the end of a story may solve this problem (19), although this proposition has not yet been tested.

Fictional versus nonfiction narratives. Although factual narratives might be preferable in some circumstances, fictional stories may also influence cancer-related attitudes and behaviors. Although not specific to cancer, Strange and Leung found that highly engaging fictional narratives about school drop out influenced recipients' judgments about causes and solutions to the problem (25). Similarly, Green and Brock found that identifying a story as fact versus fiction did not affect readers' absorption into the story (22). Evaluations of entertainment-education programs for health outcomes also suggest that fictional narratives with less transparent persuasive intent can be effective (8). Differential impact of fiction versus nonfiction narratives may depend on audience factors (e.g., perceptions of manipulation, ability to appreciate symbolism). Future research should identify conditions under which each type of narrative may be most effective.

\section{ETHICAL CHALLENGES IN USING NARRATIVE IN CANCER PREVENTION AND CONTROL}

Despite the potential benefits of narrative communication for cancer prevention and control, researchers and program developers must be cognizant of ethical responsibilities to both those providing a narrative and those exposed to the narrative. Narrative shares with other persuasive communication the potential for "epidemiological misstatement" (100), providing information that is technically correct but can be misleading to the receiver. Stories that accurately present one person's experience with cancer may not reflect known base-rate information such as the true population risk for certain cancers or the probability of survival once diagnosed. This is especially important given that narratives that are inconsistent with base-rate information can have more impact on readers' perceived base rates than do the base-rates themselves (101-103). Recognizing that a single powerful story can influence receivers' beliefs and actions even if the story is not representative, cancer communication developers need to be ethically responsible in their selection and use of narratives.

Personal experience narratives from members of the lay public may (inadvertently) include inaccurate information about diagnosis, treatment, or recovery from cancer. Constructed stories using professional actors can overcome this concern, but face the challenge of portraying in a sensitive and nonstigmatizing manner the cultural, social, and environmental realities of the intended audience. Personal narratives, which are anchored in the lived world of the narrator, provide important social, environmental, and cultural references that make the narration "real" for the audience. Several studies have reported that narratives are indeed perceived as more real, firsthand, and believable than other types of information $(23,90,104)$. Composite stories that integrate narratives from multiple individuals may allow communication developers more control over the accuracy of health content while maintaining the realism of personal experience. However, editing in this manner poses its own ethical challenges including the need to obtain consent for use and dissemination of narratives from the storytellers and to specify the extent and type of their use. It seems appropriate that a personal narrative remains the property of the storyteller and that use of the story, in part or whole, should be approved by the individual.

A narrative is usually delivered with an intended audience in mind. Outside of that intended audience, meanings and disclosures can be misunderstood. What is said or related in the company of some may be inappropriate, hurtful, or harmful to others. Thus it is important to 
consider a narrator's intended or presumed audience. In the case of personal narratives, it is also possible that revealing the actions, thoughts, or feelings of other characters in the story may be detrimental to their real-life relationships. Finally, the way a narrative describes or frames cancer causes and risks - be it positive or negative, preor postdiagnosis-has the potential to stigmatize individuals at other points on the cancer control continuum. For example, narratives describing cancer risks as "poor individual choices and behavior" might be one strategy to encourage adoption of prevention behaviors in an otherwise healthy individual but would have the unintended effect of stigmatizing individuals who are later diagnosed with cancer.

\section{CONCLUSION}

Narrative forms of communication may be especially well suited to address cancer prevention and control objectives by helping overcome resistance to prevention behaviors and health messages, facilitating processing of cancer information, providing social connections for those affected by cancer, and representing emotional and existential issues that frequently emerge after a cancer diagnosis. At the same time, narratives might be unnecessary or inappropriate for certain communication objectives, could unwittingly obscure important health messages, and may be difficult to capture or create. Although use of narrative in cancer communication is promising and growing, there is still much to learn about its effects and the conditions under which they may be optimized. We hope this article will help stimulate and guide increased scientific inquiry into narrative cancer communication.

\section{REFERENCES}

(1) Bernhardt J: Communication at the core of effective public health. American Journal of Public Health. 2004, 94: 2051-2053.

(2) Freimuth V, Quinn S: The contributions of health communication to eliminating health disparities. American Journal of Public Health. 2004, 91:2053-2055.

(3) Green M: Narratives and cancer communication. Journal of Communication. (in press).

(4) Hinyard L, Kreuter MW: Using narrative communication as a tool for health behavior change: A conceptual, theoretical, and empirical overview. Health Education and Behavior. (in press).

(5) Abbott $\mathrm{H}$ : The Cambridge Introduction to Narrative. Cambridge, UK: Cambridge University Press, 2002.

(6) Polkinghorne D: Narrative Knowing and the Human Sciences. New York: State University of New York Press, 1988.

(7) Bruner J: Actual Minds, Possible Worlds. Cambridge, MA: Harvard University Press, 1986.
(8) Singhal A, Rogers EM: Entertainment-Education: A Communication Strategy for Social Change. Mahwah, NJ: Lawrence Erlbaum Associates, 1999.

(9) Gerrig RJ: Narrative thought? Personality and Social Psychology Bulletin. 1994, 20:712-715.

(10) National Cancer Institute, U.S. National Institutes of Health: Cancer Control Continuum. Retrieved July 27, 2005 from http://cancercontrol.cancer.gov/od/continuum.html

(11) Institute of Medicine: Speaking of Health: Assessing Health Communication Strategies for Diverse Populations. Washington, DC: National Academy Press, 2002.

(12) Nielsen-Bohlman L, Panzer AM, Kindig DA: Health Literacy: A Prescription to End Confusion. Washington, DC: The National Academic Press, 2004.

(13) Rees CE, Bath PA: The information needs and source preferences of women with breast cancer and their family members: A review of the literature published between 1988 and 1998. Journal of Advanced Nursing. 2000, 21:833-841.

(14) Howard G: A narrative approach to thinking, crosscultural psychology, and psychotherapy. American Psychologist. 1991, 46:187-197.

(15) Knowles ES, Linn J (eds): Resistance and Persuasion. Mahwah, NJ: Lawrence Erlbaum Associates, 2004.

(16) Hagen KM, Gutkin TB, Wilson CP, Oats RG: Using vicarious experience and verbal persuasion to enhance self-efficacy in pre-service teachers: "Priming the pump" for consultation. School Psychology Quarterly. 1998, 13:169-178.

(17) Ng JYY, Tam SF, Yew WW, Lam WK: Effects of video modeling on self-efficacy and exercise performance of COPD patients. Social Behavior and Personality. 1999, 27:475-486.

(18) Anderson RB: Vicarious and persuasive influences on efficacy expectations and intentions to perform breast selfexamination. Public Relations Review. 2000, 26:97-114.

(19) Slater MD: Entertainment education and the persuasive impact of narratives. In Green MC, Strange JJ, Brock TC (eds), Narrative Impact: Social and Cognitive Foundations. Mahwah, NJ: Lawrence Erlbaum Associates, 2002, 157-181.

(20) Anderson RB, McMillion PY: Effects of similar and diversified modeling on African American women's efficacy expectations and intentions to perform breast selfexamination. Health Communication. 1995, 7:327-343.

(21) Morman MT: The influence of fear appeals, message design, and masculinity on men's motivation to perform the testicular self-exam. Journal of Applied Communication Research. 2000, 28:91-116.

(22) Green MC, Brock TC: The role of transportation in the persuasiveness of public narratives. Journal of Personality and Social Psychology. 2000, 79:701-721.

(23) Slater MD, Rouner D: Value-affirmative and valueprotective processing of alcohol education messages that include statistical evidence or anecdotes. Communication Research. 1996, 23:210-235.

(24) Nisbett R, Ross L: Human Inference: Strategies and Shortcomings of Social Judgment. Englewood Cliffs, NJ: Prentice Hall, 1980.

(25) Strange JJ, Leung CC: How anecdotal accounts in news and in fiction can influence judgments of a social 
problem's urgency, causes, and cures. Personality and Social Psychology Bulletin. 1999, 25:436-449.

(26) Hamill R, Wilson TD, Nisbett R: Insensitivity to sample bias: Generalizing from atypical cases. Journal of Personality and Social Psychology. 1980, 39:578-589.

(27) Taylor SE, Thompson SC: Stalking the elusive "vividness" effect. Psychological Review. 1982, 89:155-181.

(28) McDonough JE: Using and misusing anecdote in policy making. Health Affairs. 2001, Jan/Feb:207-212.

(29) Larson RJ, Woloshin S, Schwartz LM, Welch HG: Celebrity endorsements of cancer screening. Journal of the National Cancer Institute. 2005, 97:693-695.

(30) Brown ML, Potosky AL: The presidential effect: The public health response to media coverage about Ronald Reagan's colon cancer episode. Public Opinion Quarterly. 1990, 54:317-329.

(31) Lane DS, Polednak AP, Burg MA: The impact of media coverage of Nancy Reagan's experience on breast cancer screening. American Journal of Public Health. 1989, 79:1551-1552.

(32) Dal Cin S, Zanna MP, Fong GT: Narrative persuasion and overcoming resistance. In Knowles ES, Linn J (eds), Resistance and Persuasion. Mahwah, NJ: Lawrence Erlbaum Associates, 2004, 175-191.

(33) Boulware LE, Cooper LA, Ratner LE, LaVeist TA, Powe NR: Race and trust in the health care system. Public Health Reports. 2003, 118:358-365.

(34) Cox DS, Cox AD: Communicating the consequences of early detection: The role of evidence and framing. Journal of Marketing. 2001, 65:91-103.

(35) Green M, Strange J, Brock T (eds): Narrative Impact: Social and Cognitive Foundations. Mahwah, NJ: Lawrence Erlbaum Associates, 2002.

(36) Peters E, Vastfjall D, Slovic P, et al.: Numeracy and decision making. Psychological Science. 2006, 17:407-413.

(37) Rubin AM, Perse EM: Audience activity and soap opera involvement: A uses and effects investigation. Human Communication Research. 1987, 14:246-268.

(38) Horton D, Wohl RR: Mass communication and parasocial interaction. Psychiatry. 1956, 19:215-229.

(39) Picirillo MS: On the authenticity of televisual experience: A critical exploration of para-social closure. Critical Studies in Mass Communication. 1986, 3:337-355.

(40) Caughey JL: Imaginary Social Worlds: A Cultural Approach. Lincoln: University of Nebraska Press, 1984.

(41) Tan ESH: Emotion and the Structure of Film: Film as an Emotion Machine. Mahwah, NJ: Lawrence Erlbaum Associates, 1996.

(42) Oatley K: Emotions and the story worlds of fiction. In Green MC, Strange JJ, Brock TC (eds), Narrative Impact: Social and Cognitive Foundations. Mahwah, NJ: Lawrence Erlbaum Associates, 2002, 39-69.

(43) Harrison K: Does interpersonal attraction to thin media personalities promote eating disorders? Journal of Broadcasting \& Electronic Media. 1997, 41:478-500.

(44) Brown WJ, Basil MD: Media celebrities and public health: Responses to "Magic" Johnson's HIV disclosure and its impact on AIDS risk and high-risk behaviors. Health Communication. 1995, 7:345-370.

(45) Barrera Jr. M: Distinctions between social support concepts, measures, and models. American Journal of Community Psychology. 1986, 14:413-445.
(46) House JS, Landis KR, Umberson D: Social relationships and health. Science. 1988, 241:540-545.

(47) Uchino BN, Uno D, Holt-Lunstad J: Social support, physiological processes, and health. Current Directions in Psychological Science. 1999, 8:145-148.

(48) Lakey B, McCabe KM, Fisicaro SA, Drew JB: Environmental and personal determinants of support perceptions: Three generalizability studies. Journal of Personality and Social Psychology. 1996, 70:1270-1280.

(49) Giles DC: Parasocial interaction: A review of the literature and a model for future research. Media Psychology. 2002, 4:279-305.

(50) Bresnahan MJ, Murray-Johnson L: The healing Web. Health Care for Women International. 2002, 23:398-407.

(51) Turner JW, Grube, JA, Meyers J: Developing an optimal match within online communities: An exploration of CMC support communities and traditional support. Journal of Communication. 2001, 51:231-251.

(52) Barrera Jr. M, Glasgow RE, McKay HG, Boles SM, Feil EG: Do internet-based support interventions change perceptions of social support? An experimental trial of approaches for supporting diabetes self-management. American Journal of Community Psychology. 2002, 30:637-655.

(53) Shaw BR, Hawkins R, McTavish F, Pingree S, Gustafson DH: Effects of insightful disclosure within computer mediated support groups on women with breast cancer. Health Communication. 2006, 19:133-142.

(54) Burleson BR: Comforting messages: Significance, approaches, and effects. In Burleson BR, Albrecht TL, Sarason IG (eds), Communication of Social Support: Messages, Interactions, Relationships, and Community. Thousand Oaks, CA: Sage, 1994, 3-28.

(55) Israel B, Schurman S: Social support, control, and the stress process. In Glanz K, Lewis F, Rimer B (eds), Health Behavior and Health Education: Theory, Research and Practice. San Francisco: Jossey-Bass, 2002, 187-215.

(56) Kreuter MW, Strecher VJ, Glassman B: One size does not fit all: The case for tailoring print materials. Annals of Behavioral Medicine. 1999, 21:276-283.

(57) Papacharissi Z, Rubin AM: Predictors of internet use. Journal of Broadcasting and Electronic Media. 2000, 44:175-196.

(58) Block SD: Psychological considerations, growth, and transcendence at the end of life: The art of the possible. Journal of the American Medical Association. 2001, 285:2898-2905.

(59) Byock I: Dying Well: The Prospect for Growth at the End of Life. New York: Putnam, 1997.

(60) Mezirow J: Transformative Dimensions of Adult Learning. San Francisco: Jossey-Bass, 1991.

(61) Mathieson CM, Stam HJ: Renegotiating identity: Cancer narratives. Sociology of Health and Illness. 1995, 17:283-306.

(62) Armstrong L: It's Not About the Bike: My Journey Back to Life. New York: Putnam, 2000.

(63) Frank AW: The Wounded Storyteller. Chicago: University of Chicago Press, 1995.

(64) Lin HR, Bauer-Wu SM: Psycho-spiritual well-being in patients with advanced cancer: An integrative review of the literature. Journal of Advanced Nursing. 2003, 44: 69-80. 
(65) Damasio AR: Descartes' Error: Emotion, Reason and the Human Brain. New York: Putnam, 1993.

(66) Ezzy D: Illness narratives: Time, hope, and HIV. Social Science and Medicine. 2000, 50:605-617.

(67) Carlick A, Biley FC: Thoughts on the therapeutic use of narrative in the promotion of coping with cancer. European Journal of Cancer Care. 2004, 13:308-317.

(68) Kleinman A: The Illness Narratives: Suffering, Healing, and the Human Condition. New York: Basic Books, 1988.

(69) Pennebaker JW: Telling stories: The health benefits of narrative. Literature \& Medicine. 2000, 19:3-18.

(70) Chochinov HM: Dignity-conserving care: A new model for palliative care: Helping the patient feel valued. Journal of the American Medical Association. 2002, 28: 2253-2260.

(71) Radley A: The aesthetics of illness: Narrative, horror and the sublime. Sociology of Health and Illness. 1999, 21: 778-796.

(72) Antoni M, Lehman J, Kilbourn K, et al.: Cognitive-behavioral stress management intervention decreases the prevalence of depression and enhances benefit finding among women under treatment for early-stage breast cancer. Health Psychology. 2001, 20:20-32.

(73) Tedeschi RG, Calhoun LG: The posttraumatic growth inventory: Measuring the positive legacy of trauma. Journal of Traumatic Stress. 1996, 9:455-471.

(74) Spiegel D: Living Beyond the Limits: New Hope and Help for Facing Life-Threatening Illness. New York: Random House, 1993.

(75) Lannamann JW, Harris LM, Bakos AD, Baker KJ: Ending the end-of-life communication impasse: A dialogic intervention. In Sparks L, O'Hair D, Kreps G (eds), Cancer Communication and Aging. Cresskill, NJ: Hampton Press, in press.

(76) Plexus Institute: Stories: Complexity in Action. Retrieved December 13, 2005 from http://www.plexusinstitute.com

(77) Charmaz K: Discoveries of self in illness. In Charmaz K, Paterniti DA (eds), Health, Illness and Healing: Society, Social Context, and Self. Los Angeles, CA: Roxbury, 1998, chapter 9.

(78) Frankl VR: Man's Search for Meaning: An Introduction to Logotherapy (3rd Ed.). New York: Touchstone Books, 1984.

(79) Labouvie-Vief G: Wisdom as integrated thought: Historical and developmental perspectives. In Sternberg R (ed), Wisdom: It's Nature, Origins, and Development. New York: Cambridge University Press, 1990, 52-85.

(80) McGregor BA, Antoni MH, Boyers A, et al.: Cognitivebehavioral stress management increases benefit finding and immune function among women with early-stage breast cancer. Health Psychology. 2001, 20:20-32.

(81) Spiegel D, Bloom JR, Kraemer HC, Gottheil E: Effect of psychosocial treatment on survival of patients with metastatic breast cancer. The Lancet. 1989, 2:888-891.

(82) Spiegel D, Sephton S: Psychoneuroimmune and endnocrine pathway in cancer: Effects of stress and support. Seminars in Clinical Neuropsychiatry. 2001, 6:252-265.

(83) Shaw B, Hawkins R, McTavish F, Pingree S, Gustafson D: Effects of insightful disclosure within computer-mediated support groups on women with breast cancer. Health Communication. (in press).
(84) Chelf J, Deshler A, Hillman S, Durazo-Arvizo R: Storytelling: A strategy for living and coping with cancer. Cancer Nursing. 2000, 23:1-5.

(85) Coreil J, Wilke J, Pintado I: Cultural models of illness and recovery in breast cancer support groups. Qualitative Health Research. 2004, 14:905-923.

(86) Bruner J: The narrative construction of reality. Critical Inquiry, 1991, 18:1-21.

(87) Bennett P, Howard N: Rationality, emotion and preference change: Drama theoretic models of choice. European Journal of Operational Research. 1996, 92:603-614.

(88) Hatcher J: The Art and Craft of Playwriting. Cincinnati, OH: Storey Press, 1996.

(89) Hicks ND: Screenwriting 101: The Essence and Craft of Feature Film Writing. New York: McNaughton and Guner, 1999.

(90) Simons H, Berkowitz N, Moyer R: Similarity, credibility, and attitude change: A review and a theory. Psychological Bulletin. 1970, 73:1-16.

(91) Fleming M, Petty R: Identity and persuasion: An elaboration likelihood approach. In Terry D, Hogg M (eds), Attitudes, Behavior, and Social Context: The Role of Norms and Group Membership. Mahwah, NJ: Lawrence Erlbaum Associates, 2000, 171-199.

(92) Chaiken S: The heuristic model of persuasion. In Zanna MP, Olsen JM, Herman CP (eds), Social Influence: The Ontario Symposium (Vol. 5). Hillsdale, NJ: Lawrence Erlbaum Associates, 1987, 3-39.

(93) Bailey EJ, Erwin DO, Belin P: Using cultural beliefs and patterns to improve mammography utilization among African-American women: The Witness Project. Journal of the National Medical Association. 2000, 92:136-142.

(94) Slater MD, Buller DB, Waters E, Archibeque M, LeBlanc $\mathrm{M}$ : A test of conversational and testimonial messages versus didactic presentations of nutrition information. Journal of Nutrition Education and Behavior. 2003, 35:255-259.

(95) Campbell RG, Babrow AS: The role of empathy in responses to persuasive risk communication: Overcoming resistance to HIV prevention messages. Health Communication. 2004, 16:159-182.

(96) Shelton ML, Rogers RW: Fear-arousing and empathyarousing appeals to help: The pathos of persuasion. Journal of Applied Social Psychology. 1981, 11:366-378.

(97) Fiske ST: Social Beings: A Core Motives Approach to Social Psychology. Hoboken, NJ: Wiley, 2004.

(98) Erwin DO, Spatz TS, Stotts RC, Hollenberg JA, Deloney LA: Increasing mammography and breast self-examination in African American women using the Witness Project model. Journal of Cancer Education. 1996, 11:210-215.

(99) Priester JR, Petty RE: The influence of spokesperson trustworthiness on message elaboration, attitude strength, and advertising effectiveness. Journal of Consumer Psychology. 2003, 13:408-421.

(100) Bayer R: Module 6: Ethics of Health Promotion and Disease Prevention. In Jennings B, Kahn J, Mastroianni A, Parker LS (eds), Ethics \& Public Health Module Curriculum. Retrieved September 6, 2005 from http:// www.asph.org/document.cfm?page $=782$.

(101) Zillman D, Brosius H: Exemplification in Communication: The Influence of Case Reports on the Perception of Issues. Mahwah, NJ: Lawrence Erlbaum Associates, 2000. 
(102) Ubel PA, Jepson C, Baron J: The inclusion of patient testimonials in decision aids: Effects on treatment choices. Medical Decision Making. 2001, 21:60-68.

(103) Fagerlin A, Wang C, Ubel PA: Reducing the influence of anecdotal reasoning on people's health care decisions: Is a picture worth a thousand statistics? Medical Decision Making. 2005, 25:398-405.
(104) Greene K, Brinn LS: Messages influencing college women's tanning bed use: Statistical versus narrative evidence format and a self-assessment to increase perceived susceptibility. Journal of Health Communication. 2003, 8: 443-461. 